\title{
Predictivity Strength of the Spatial Variability of Phenanthrene Sorption Across Two Sandy Loam Fields
}

\author{
Antonio Soares • Marcos Paradelo • Per Moldrup • \\ Cristina Delerue-Matos $\cdot$ Lis W. de Jonge
}

\begin{abstract}
Sorption is commonly agreed to be the major process underlying the transport and fate of polycyclic aromatic hydrocarbons (PAHs) in soils. However, there is still a scarcity of studies focusing on spatial variability at the field scale in particular. In order to investigate the variation in the field of phenanthrene sorption, bulk topsoil samples were taken in a $15 \times 15$-m grid from the plough layer in two sandy loam fields with different texture and organic carbon (OC) contents (140 samples in total). Batch experiments were performed using the adsorption method. Values for the partition coefficient $K_{\mathrm{d}}\left(\mathrm{L} \mathrm{kg}^{-1}\right)$ and the organic carbon partition coefficient $K_{\mathrm{OC}}\left(\mathrm{L} \mathrm{kg}^{-1}\right)$ agreed with the most frequently used
\end{abstract}

models for PAH partitioning, as OC revealed a higher affinity for sorption. More complex models using different OC compartments, such as non-complexed organic carbon (NCOC) and complexed organic carbon (COC) separately, performed better than single $K_{\mathrm{OC}}$ models, particularly for a subset including samples with Dexter $n<10$ and OC $<0.04 \mathrm{~kg} \mathrm{~kg}^{-1}$. The selected threshold revealed that $K_{\mathrm{OC}}$-based models proved to be applicable for more organic fields, while twocomponent models proved to be more accurate for the prediction of $K_{\mathrm{d}}$ and retardation factor $(R)$ for less organic soils. Moreover, OC did not fully reflect the changes in phenanthrene retardation in the field with lower OC content (Faardrup). Bulk density and available water content influenced the phenanthrene transport mechanism phenomenon.

Keywords Sorption · Soil organic carbon · Complexed organic carbon - Non-complexed organic carbon . Phenanthrene $\cdot$ Field-scale $\cdot$ Leaching risk

\section{Introduction}

Sorption and desorption together with degradation are key processes in the fate of polycyclic aromatic hydrocarbons (PAHs) in soils (Magee et al. 1991; Chung and Alexander 2002; Reeves et al. 2004). Particularly, sorption is of great interest because of the high affinity of PAHs to soil organic matter (SOM) and their low solubility (Yang et al. 2013). 
The retention of hydrophobic organic contaminants (HOCs) such as pesticides and PAHs is known to be influenced by different processes occurring in the soil matrix, their fate being controlled in particular by the sorption on SOM (de Jonge et al. 2000; Huang et al. 2003; de Jonge et al. 2008). The organic carbon partition coefficient $\left(K_{\mathrm{OC}}\right)$ reveals the affinity of contaminants for sorption to SOM, and thus it is widely used by scientists to predict the environmental fate of organic compounds (Wauchope et al. 2002). However, the prediction of sorption from organic carbon (OC) content may be influenced by SOM heterogeneity, solution chemistry (pH and ionic strength) and soil minerals (clay particles) (Schlautman and Morgan 1993; Njoroge et al. 1998; Jones and Tiller 1999; Celis et al. 2006; Ping et al. 2006; de Jonge et al. 2008). Furthermore, the interaction of PAH with SOM is also influenced by the contaminant's intrinsic properties, such as structure and polarity (Laor et al. 1998; Huang et al. 2003).

The predictive ability of the $K_{\mathrm{OC}}$ coefficient may fail in soils with a low OC content (Schwarzenbach and Westall 1981). Celis et al. (2006) found weak relationships between soil OC content and sorption coefficients for phenanthrene and dibenzofuran, suggesting that sorption cannot be derived exclusively from the OC content. Similarly, Soares et al. (2013) studied the $K_{\mathrm{OC}}$ of cultivated topsoils and subsoils, concluding that the phenanthrene sorption behaviour differed markedly depending on the OC content of the samples, with higher $K_{\mathrm{OC}}$ values for topsoils, while de Jonge et al. (2008) suggested that $K_{\mathrm{OC}}$ values were significantly inversely correlated with clay content for both pyrene and phenanthrene, emphasizing the importance of soil minerals. The role of different soil properties, such as water content (Cousin et al. 1999) and cation-exchange capacity and surface area (Chung and Alexander 2002), has also been highlighted, particularly for the dissipation of less persistent hydrocarbons.

In order to predict the mobility of PAHs in soil and groundwater from the $\mathrm{OC}$ content, two linear sorption equilibrium models can be applied to identify the partitioning coefficient $K_{\mathrm{d}}\left(\mathrm{L} \mathrm{kg}^{-1}\right)$ between water and non-polar organic contaminants: the Karickhoff et al. and the Abdul et al. models (Karickhoff et al. 1979; Abdul et al. 1987).

Recently, Soares et al. (2013) developed two new models for phenanthrene sorption, where the first model yielded values of $K_{\mathrm{OC}}$ in between those of the Karickhoff et al. (1979) and the Abdul et al. (1987) models (i.e. 15,000 $\mathrm{L} \mathrm{kg}^{-1}$ ) and closer to a lesser known model by Karickhoff (1981) producing a $K_{\mathrm{OC}}$ value of $14,918 \mathrm{~L} \mathrm{~kg}^{-1}$, while a second linear model included complexed organic carbon (COC) and non-complexed organic carbon (NCOC) based on Dexter et al. (2008). According to the Dexter ratio, $n=$ clay/OC only if $n$ is below ten is the NCOC fraction present in soil, thus OC saturated, and if above it, is considered to be OC depleted. The second Soares et al. (2013) model extended the physical argument of Dexter et al. (2008) to the soil sorption capacity.

The spatial distribution of organic contaminants such as pesticides (Kiersch et al. 2010), and PAHs (Liang et al. 2012; Cachada et al. 2012) has come under increasing scrutiny in recent years. It is commonly agreed that their concentration tends to show a large horizontal variability (Muller et al. 2003) along with soil physical and chemical properties (Nielsen et al. 1973). However, there is still insufficient knowledge about PAH retention rates with horizontal spatial heterogeneity. The spatial distribution of HOC degradation may depend on the interaction between the bioavailability of contaminants and the biophysicochemical features of soils (Charnay et al. 2005).

That soil properties are inherently variable has been clearly identified. Goderya (1998) suggested that soil pedogenesis may affect the variation of soil properties across a field by influencing the topography, thus leading to different patterns of hydrological processes and establishing irregularities in the deposition of parent material. Moreover, different management practices increase the spatial variability of soil properties due to the redistribution of topsoil from the upper slope to lower slopes caused by tillage (Gregorich and Anderson 1985; Umali et al. 2012).

In this study, we aimed to assess the ability of the previously proposed models to predict the spatial variability of phenanthrene retention. This analysis was conducted on two independent sandy loam fields in Denmark with different ranges of OC content by means of batch equilibration experiments. The influence of soil properties was evaluated in order to determine the degree of phenanthrene sorption distribution at the field scale. It is believed that the results will provide substantial new knowledge on the retention of phenanthrene, allowing for a better understanding of the leaching of contaminants at field scale. 


\section{Materials and Methods}

\subsection{Chemicals}

Phenanthrene $\left(\mathrm{C}_{14} \mathrm{H}_{10}\right)$, as ring-UL- ${ }^{14} \mathrm{C}$-phenanthrene (specific activity $=55 \mathrm{mCi} \mathrm{mmol}^{-1}$; radiochemical purity $\geq 99 \%$ ) was purchased from American Radiolabeled Chemicals Inc. (St. Louis, MO).

\subsection{Soils}

Two sandy loam fields in Denmark (Faardrup and Estrup) (Fig. 1) were selected for this study, covering different ranges in $\mathrm{OC}$ content. The clay fraction is for both soils dominated by smectite but also contains vermiculite, illite, kaolinite and quartz (Lindhardt et al. 2001). The two fields are part of the Danish Pesticide Leaching Assessment Programme (PLAP). This programme began in 1998 and has since that time been monitoring the leaching of pesticides or their degradation products to groundwater and tile drains under actual field conditions. Further details about PLAP, the two field site locations, geological properties, soil hydrology and monitoring equipment can be found elsewhere (Lindhardt et al. 2001; Kjaer et al. 2007; Kjaer et al. 2011).

The field in Faardrup is located in southern Zealand, $3 \mathrm{~km}$ from the town of Flakkebjerg (Fig. 1a). It covers a cultivated area of $2.3 \mathrm{ha}(150 \times 160 \mathrm{~m})$. Since 2000 , and according to the PLAP reports (Lindhardt et al. 2001), several harvests have been taken. The last seed bed preparation (before sampling) for spring barley at a soil depth of $6 \mathrm{~cm}$ occurred in April 2010, with the barley harvested in July 2010. At the time of sampling (April, 2011), the field was covered with red fescue (Festuca rubra L.). Ninety-five bulk soil samples were taken from the topsoil (0-20-cm depth) in a $15 \times 15-\mathrm{m}$ grid (Fig. 1b). Simultaneously, cylindrical cores of $20 \times$ $20 \mathrm{~cm}$ were sampled at the same points for other purposes, such as bulk density and water content determination. Bulk density and water content were used to calculate the retardation factor $(R)$ (Delle Site 2000).

The Estrup field measures 1.3 ha $(105 \times 120 \mathrm{~m})$ (Fig. 1c) and is located in central Jutland in the Vejen municipality (Fig. 1a). The soil had previously been disturbed when winter wheat was harvested in August 2011 and when spring barley was sown in March 2012. Sampling took place after the harvest of the spring barley. Forty-five bulk soil samples, together with $20 \times$ 20-cm cores, were taken from the topsoil in September 2012, following the same method as described for Faardrup.

\subsection{Physical and Chemical Properties}

Soil texture was determined according to Gee and Or (2002) using the combined sieve/hydrometer method. Organic carbon (OC) was determined on a LECO analyser coupled with an infrared $\mathrm{CO}_{2}$ Flash $2000 \mathrm{NC}$ detector (Thermo Fisher Scientific Inc., USA).

The $\mathrm{pH}$ was measured in a 1:4 by volume soil:water solution and electrical conductivity (EC) was measured in a 1:9 soil:water solution. Bulk density and in situ available water content were determined from the weights of the $20 \times 20$-cm cores in the field and after drying at $105^{\circ} \mathrm{C}$.

\subsection{Sorption Experiments}

The phenanthrene sorption coefficient was obtained by a batch equilibration experiment. Triplicate soil aliquots $(0.5 \mathrm{~g})$ were hydrated with $0.5 \mathrm{~mL}$ of $0.003 \mathrm{M} \mathrm{CaCl}_{2}$ for $24 \mathrm{~h}$, using glass centrifuge tubes closed with Teflon caps. Hereafter, $9 \mathrm{~mL}$ of a $0.0405 \mathrm{mg} \mathrm{L}^{-1}$ aqueous solution of ${ }^{14} \mathrm{C}$ phenanthrene $\left(22.4 \times 10^{4} \mathrm{~Bq} \mathrm{~L}^{-1}\right)$ was added, and the samples were rotated end-over-end $(30 \mathrm{rpm})$ at $20 \pm 2{ }^{\circ} \mathrm{C}$ for $24 \mathrm{~h}$. Sodium azide $\left(\mathrm{NaN}_{3}\right)$ in a concentration of $1.0 \mathrm{~g} \mathrm{~L}^{-1}$ was added to the input solution to avoid microbial degradation of phenanthrene. A preliminary kinetic experiment showed that apparent equilibrium was reached within $24 \mathrm{~h}$.

After equilibration, the samples were centrifuged at $5000 \mathrm{rpm}$ for $1 \mathrm{~h}$, and $3 \mathrm{~mL}$ of the supernatant solution was taken for analysis using a glass pipette. Phenanthrene concentration was determined by liquid scintillation counting (Packard $2250 \mathrm{CA}$, Downers Grove, IL) mixing the $3 \mathrm{~mL}$ of supernatant with $17 \mathrm{~mL}$ of Ultima Gold scintillation cocktail (Packard, Downers Grove, IL). Radioactivity measurements were transformed to concentration values using the ${ }^{14} \mathrm{C}$ activity of the initial phenanthrene solutions. The amount of phenanthrene sorbed was calculated by the difference between the initial and final solution concentrations. Input solutions without soil were also shaken for $24 \mathrm{~h}$, in order to get the initial concentrations of the samples. 


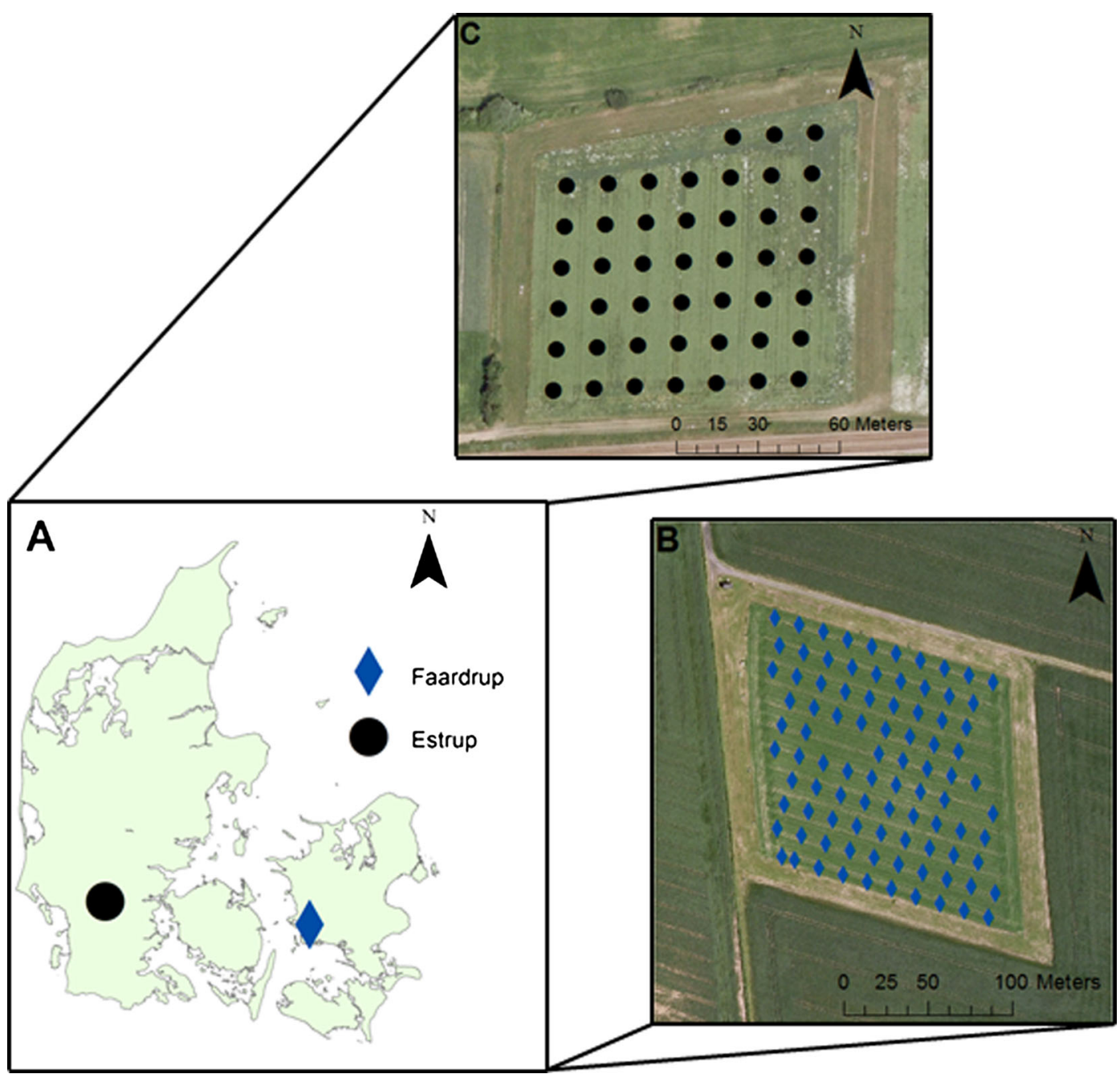

Fig. 1 Location of Danish fields: Faardrup and Estrup (a), sampling grid at Faardrup (b) and at Estrup (c)

\subsection{Sorption Theory}

The linear sorption isotherm can be described by the following equation:

$\mathrm{S}=K_{\mathrm{d}} \times C_{\mathrm{eq}}$

where $S$ is the amount of chemical sorbed $\left(\mathrm{mg} \mathrm{kg}^{-1}\right)$ at the equilibrium concentration, $C_{\text {eq }}\left(\mathrm{mg} \mathrm{L}^{-1}\right)$, and $K_{\mathrm{d}}$ $\left(\mathrm{L} \mathrm{kg}^{-1}\right)$ is the linear sorption (partition) coefficient. The organic carbon sorption coefficient $K_{\mathrm{OC}}\left(\mathrm{L} \mathrm{kg}^{-1}\right)$ is defined by the equation:

$K_{\mathrm{OC}}=\frac{K_{\mathrm{d}}}{f_{\mathrm{oc}}}$

where $f_{\mathrm{OC}}$ is the fraction of OC in the soil $\left(\mathrm{kg} \mathrm{kg}^{-1}\right)$.

\subsection{Statistical and Spatial Analysis}

Linear relationships between sorption coefficients and soil properties were studied by means of the Pearson correlation coefficient at the significance levels $P<0.05,<0.01$ and $<0.001$. The models were validated by calculating the coefficient of variation of the root mean square error (CVRMSE).

Contour plots, using interpolation techniques for comparative mapping of soil parameters, $K_{\mathrm{d}}$, and retardation factors were obtained from empirical Bayesian kriging in ArcMap 10.1. Variograms were calculated and fitted based on root mean square error (RMSE). 


\section{Results and Discussion}

\subsection{Soil Properties}

The general soil properties of both fields are shown in Table 1. The content of OC was higher in the Estrup field ( 0.018 to $\left.0.084 \mathrm{~kg} \mathrm{~kg}^{-1}\right)$ than at Faardrup (0.011 to $0.017 \mathrm{~kg} \mathrm{~kg}^{-1}$ ). The clay content was slightly higher at Faardrup, ranging from 0.10 to $0.19 \mathrm{~kg} \mathrm{~kg}^{-1}$, compared with 0.06 to $0.14 \mathrm{~kg} \mathrm{~kg}^{-1}$ at Estrup.

Figure 2 shows $\mathrm{OC}$ as a function of clay for Faardrup and Estrup. Three lines representing $n=$ 1.5, 10 and 18 were shown to include the vast majority of the 140 samples. According to Dexter et al. (2008), $n$ values below ten indicate the presence of OC non-complexed by clay and above ten that all OC is complexed by clay. Most Faardrup soils are closely concentrated around Dexter $n=10$, with a few exceptions. Dexter $n$ for the Estrup soil was lower than 10 with values down to 1.5 .

We calculated COC and NCOC for $n=10$ according to Dexter et al. (2008):

$$
\begin{aligned}
\mathrm{COC} & =\mathrm{OC} \text { if } \mathrm{OC}<\left(\frac{\text { clay }}{n}\right) \text { else COC } \\
& =\left(\frac{\text { clay }}{n}\right)
\end{aligned}
$$

$$
\begin{aligned}
\mathrm{NCOC} & =\mathrm{OC}-\text { if }(\mathrm{OC}-\mathrm{COC})>0 \text { else } \mathrm{NCOC} \\
& =0
\end{aligned}
$$

All samples at Estrup exceeded the amount of OC that can be complexed by the amount of clay present; NCOC ranged from 0.005 to $0.071 \mathrm{~kg} \mathrm{~kg}^{-1}$ and COC from 0.005 to $0.014 \mathrm{~kg} \mathrm{~kg}^{-1}$ (Table 1). At Faardrup, $70 \%$ of the samples followed the same arrangement (Dexter $n<10$; NCOC from 0 to $0.007 \mathrm{~kg} \mathrm{~kg}^{-1}$, COC from 0.011 to $0.017 \mathrm{~kg} \mathrm{~kg}^{-1}$ ). It is expected that NCOC will be more accessible to phenantrene sorption.

Both fields had similar average values of $\mathrm{pH}$ of 6.7. However, the $\mathrm{pH}$ range at Faardrup was wider with values as low as 5.84. The EC was slighty lower at Estrup than at Faardrup.

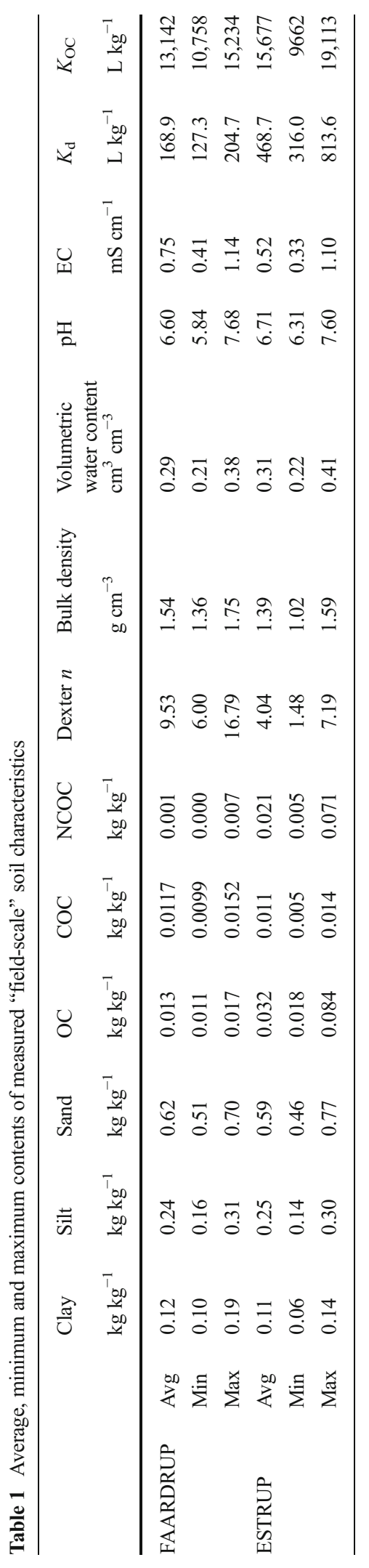




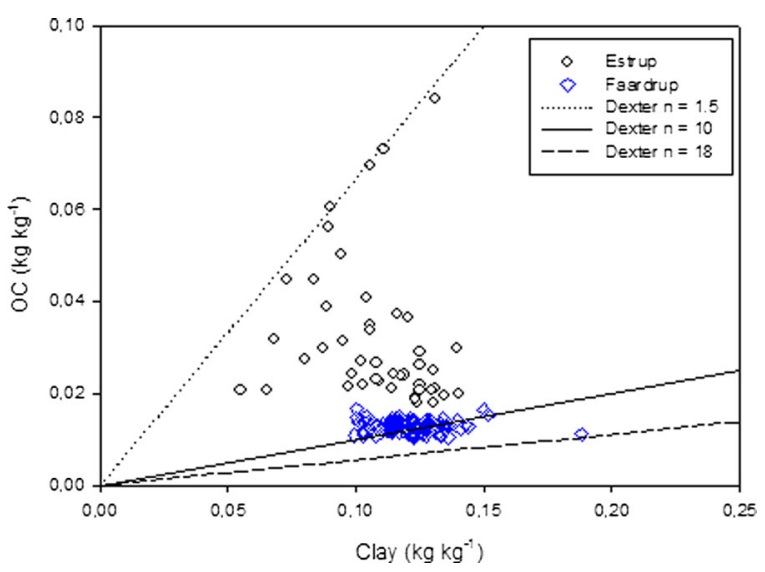

Fig. 2 Organic carbon content (OC) as a function of clay content for all samples (Dexter $n$ ). Clay:OC ratios representing $n=1.5, n=$ 10 and $n=18$ are shown

\subsection{Sorption Coefficients and Correlations with Soil Properties}

Phenanthrene sorption coefficients ranged from 127 to $205 \mathrm{~L} \mathrm{~kg}^{-1}$ (average $169 \mathrm{~L} \mathrm{~kg}^{-1}$ ) at Faardrup and from 316 to $814 \mathrm{~L} \mathrm{~kg}^{-1}$ (average $469 \mathrm{~L} \mathrm{~kg}^{-1}$ ) at Estrup (Table 1). The OC partition coefficients $\left(K_{\mathrm{OC}}\right)$ ranged from 10,758 to $15,234 \mathrm{~L} \mathrm{~kg}^{-1}$ (average $13,142 \mathrm{~L} \mathrm{~kg}^{-1}$ ) at Faardrup and 9662 to $19,113 \mathrm{~L} \mathrm{~kg}^{-1}$ (average $15,677 \mathrm{~L} \mathrm{~kg}^{-1}$ ) at Estrup, which are relatively close to the value of $14,918 \mathrm{~L} \mathrm{~kg}^{-1}$ proposed by Karickhoff (1981) and the $15,000 \mathrm{~L} \mathrm{~kg}^{-1}$ proposed by Soares et al. (2013) for topsoils. Similar ranges were found for agricultural soils (Celis et al. 2006; Kumari et al. 2014).

Pearson's correlation coefficients for sorption parameters and soil property relationships at Faardrup and Estrup are shown in Table 2. Generally, better correlations were found for Estrup.

For Estrup, $K_{\mathrm{d}}$ was strongly positively correlated with OC $(r=0.96)$ and NCOC $(r=0.96)$ and negatively with Dexter $n(r=-0.83)$; to a lesser extent, $K_{\mathrm{d}}$ was also correlated with sand $(r=-0.40)$ and EC $(r=0.30)$. At Faardrup, $K_{\mathrm{d}}$ was strongly correlated with OC ( $r=$ $0.79)$, NCOC $(r=0.61)$, Dexter $n(r=-0.71)$ and $\mathrm{pH}$ $(r=-0.53)$. Significant correlations were also found with clay and COC $(r<0.30)$. The higher affinity for sorption of NCOC than COC agrees well with the findings of Soares et al. (2013). The complexing effect of clay influences the sorptive properties of the organic matter, reducing the number of sorption sites (Jones and Tiller 1999).
In Estrup, $K_{\mathrm{OC}}$ decreased with increasing $\mathrm{OC}$ and NCOC ( $r=-0.91$ for both cases). Sand content and Dexter $n$ correlated positively with $K_{\mathrm{OC}}(r=0.52$ and 0.73 , respectively). At Faardrup $K_{\mathrm{OC}}$ was slightly negatively correlated with $\mathrm{pH}$, clay, OC and COC (Table 2). The negative correlation of $K_{\mathrm{OC}}$ with OC and NCOC at Estrup suggests that the capacity of organic matter to sorb phenanthrene decreases at higher OC contents. This decreasing efficiency can be related to the SOM quality and the amount of OC that can be readily retained (Amellal et al. 2006). The hydric regime, microbial activity and other factors can change the degradation rates, affecting the composition of the SOM (e.g., Styrishave et al. 2012). Because the OC range at Faardrup was lower and narrower, this effect disappeared here and $K_{\mathrm{OC}}$ varied much less.

In terms of the relationship of $K_{\mathrm{OC}}$ with $K_{\mathrm{d}}$, this was positively correlated at Faardrup $(r=0.37)$ and negatively at Estrup $(r=-0.80)$. This confirms that the sorption capacity at Estrup did not increase linearly with $\mathrm{OC}$ as would be expected (particularly for $\mathrm{OC}>0.04 \mathrm{~kg} \mathrm{~kg}^{-1}$ ).

Soil organic matter heterogeneity has been found to affect the soil sorption capacity of organic compounds. Ran et al. (2002) found differences in the sorption linearity of PAHs with the proportion of soft/condensed SOM. This proportion controls the availability of sorption sites on the SOM. Huang et al. (2003) highlighted the differences between soil OM types, such as humic acids, kerogen and black carbon. While the humic acids revealed fast and relatively linear sorption levels, the last two have stiff structures, are less polar than humic acids and show a lower degree of sorption.

The negative effect of $\mathrm{pH}$ on sorption at Faardrup is in line with the findings of previous studies (Murphy et al. 1990; Laor et al. 1998). Increasing $\mathrm{pH}$ increases the polarity of the humic substances, which lowers their affinity to hydrophobic compounds (Schlautman and Morgan 1993; Ping et al. 2006). Simultaneously, the type of media (e.g. mineralogy), along with low $\mathrm{pH}$ values, may also influence the amount of disposable humic substances available that favour the interaction between $\mathrm{OM}$ and the compound (Laor et al. 1998). Moreover, $\mathrm{pH}$ affects microbial populations and their metabolism, resulting in differences in organic matter quality (de Jonge et al. 2008). 
Table 2 Pearson's correlation coefficient, $r$

$* P<0.05, * * P<0.01$,

$* * * P<0.001$

\subsection{Validity of OC Models}

As we stated above, OC has the strongest influence on phenanthrene sorption. Different models have proposed a linear relation between $K_{\mathrm{d}}$ and the OC content $\left(f_{\mathrm{OC}}\right)$ :

Karickhoff et al. (1979):

$K_{\mathrm{d}}=22,909[\mathrm{OC}]$

Karickhoff (1981):

$K_{\mathrm{d}}=14,918[\mathrm{OC}]$

Abdul et al. (1987):

$K_{\mathrm{d}}=7,461[\mathrm{OC}]$

Soares et al. (2013) model I:

$K_{\mathrm{d}}=15,027[\mathrm{OC}]$

Figure 3a compares the presented experimental results with previous models (Karickhoff et al. 1979; Karickhoff 1981; Abdul et al. 1987). The regression line of both fields (solid black line) gave a $K_{\mathrm{OC}}$ of $13,369 \mathrm{~L} \mathrm{~kg}^{-1}$, which is closer to that suggested by Karickhoff in 1981 (blue line).

This was expected since the Abdul model was developed from a lower range of OC $\left(0.004-0.020 \mathrm{~kg} \mathrm{~kg}^{-1}\right)$ and the Karickhoff et al. (1979) model used samples with a limited range of OC $\left(0.028-0.033 \mathrm{~kg} \mathrm{~kg}^{-1}\right)$. Therefore, they are hardly representative of soils with a wide OC range. We noticed that the sorption behaviour for Estrup diverged from previous models when OC $>0.04 \mathrm{~kg} \mathrm{~kg}^{-1}$. According to the $95 \%$ prediction intervals (dotted lines), four Estrup samples fell outside, with
OC contents higher than $0.055 \mathrm{~kg} \mathrm{~kg}^{-1}$. These highly organic samples presumably revealed a significant degree of OC saturation as previously discussed, thus leading to a non-proportional degree of sorption, revealed by the non-linear trend (Fig. 3a) for samples with OC content above $0.04 \mathrm{~kg} \mathrm{~kg}^{-1}$.

For a more accurate comparison between models, the samples with Dexter $n$ values above 10 and OC contents above $0.04 \mathrm{~kg} \mathrm{~kg}^{-1}$ were excluded (Fig. 3). This resulted in a value of $K_{\mathrm{OC}}$ of $15,267 \mathrm{~L} \mathrm{~kg}^{-1}$ for the data subset which was closer to that of the Karickhoff (1981) model.

A new model, which takes in account the OC-clay interactions, was also introduced by splitting the OC into COC and NCOC (Soares et al. 2013):

Soares et al. (2013) model II:

$K_{\mathrm{d}}=12,697[\mathrm{COC}]+18,454[\mathrm{NCOC}]$

These results revealed the stronger affinity of phenanthrene to $\mathrm{NCOC}$, with a NCOC partition ratio $\left(18,454 \mathrm{~L} \mathrm{~kg}^{-1}\right)$ of around 1.5 times higher than the COC partition ratio $\left(12,697 \mathrm{~L} \mathrm{~kg}^{-1}\right)$.

The coefficient of variation of the root square mean error (CV-RMSE) was calculated to elucidate which model would give a better fit to the experimental data for each field (Table 3). The Karickhoff (1981) model fitted the Estrup data better, while the Soares et al. model II showed the best prediction for Faardrup. On the other hand, by establishing the subset that excluded samples with $n>10$ and $\mathrm{OC}>0.04 \mathrm{~kg} \mathrm{~kg}^{-1}$, the Soares et al. model II was found to be a better predictor for $K_{\mathrm{d}}$ in both fields with a slightly better fit $(\mathrm{CV}-\mathrm{RMSE}=0.07)$ at Faardrup and a significantly better fit at Estrup (CV$\mathrm{RMSE}=0.11)$. With a lower OC content, like at 

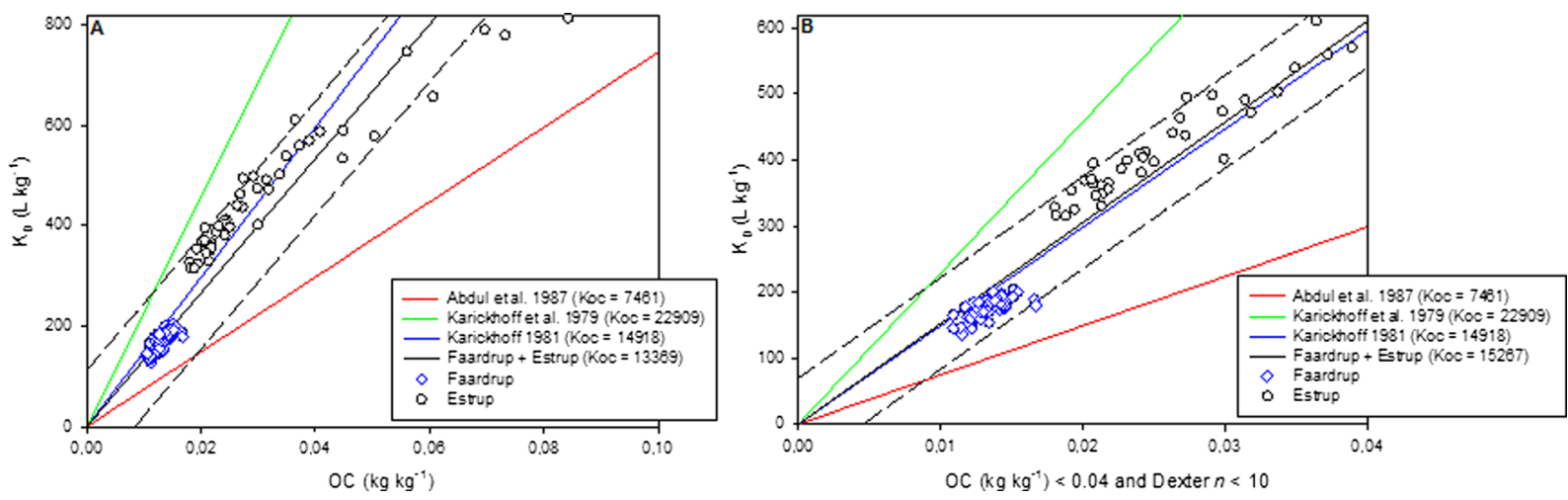

Fig. $3 K_{\mathrm{d}}$ as a function of organic carbon (OC) for all Faardrup and Estrup samples (a) and for samples that $(n<10$ and $\mathrm{OC}<$ $\left.0.04 \mathrm{~kg} \mathrm{~kg}^{-1}\right)(\mathbf{b})$

Faardrup, the interaction between clay and $\mathrm{OC}$ becomes more conducive to phenanthrene sorption, where available sorption sites depend on the presence of NCOC. In our previous study (Soares et al. 2013), we suggested that the NCOC content will limit phenanthrene sorption when $\mathrm{OC}$ contents are below $0.02 \mathrm{~kg} \mathrm{~kg}^{-1}$. Hassett and Banwart (1989) similarly stated that interactions between clay and SOM affect the sorption of organic compounds when SOM is lower than $6 \%$. The phenanthrene sorption capacity of a soil cannot be fully described using $K_{\mathrm{OC}}$ but by the sum of the individual sorptions in each organic and mineral fraction (Luo et al. 2008; DeLapp and LeBoeuf 2004). The division of the soil into two sorption compartments (NCOC and $\mathrm{COC}$ ) is an effective tool to improve the prediction of phenanthrene sorption without a detailed study of SOM fractions, which is time-consuming and costly. The following analyses that included estimations of $K_{\mathrm{d}}$ were based on the Soares et al. (2013) model II, in order to better evaluate the two-compartment model against actual soil processes.

\subsection{Field-Scale Variation}

Field-scale prediction was performed by analysing spatial trends for phenanthrene sorption. Figure 4 presents contour plots of OC, experimental $K_{\mathrm{d}}$ and estimated $K_{\mathrm{d}}$ by Soares et al. model II for both fields. As expected, higher values of $K_{\mathrm{d}}$ (measured and estimated) corresponded to the areas with higher OC contents. At Faardrup, these areas are located to the north but also in a smaller area to the south. At Estrup, the highest sorption capacity was found in one specific area located in the southwestern part of the field.

The results show that the spatial variation of the soil parameters, and in particular OC content, had a major influence on the spatial variability of the sorption coefficients. Sorption coefficients for atrazine, isoproturon and metamitron have been found to spatially correlate with OC and clay content within a 135-ha catchment (Charnay et al. 2005). Besides sorption, OC content has also been found to play a role in pesticide mineralization and microbial activity (Vinther et al. 2008). Gaultier et al. (2006) found that for the A horizon, regression models including only soil OC and carbonate content were sufficient to successfully predict 2,4-D sorption.

The spatial distribution of the residuals is shown in Fig. 5. The residuals for Faardrup (Fig. 5a, b) were almost homogenously distributed across the field. Two small areas (north-central and south-central) showed some overestimation of the model, reflected in the negative values of the residuals. The common factor for
Table 3 Former model's data for Faardrup and Estrup. Soares et al. model II being $K_{\mathrm{d}}=12,697$ $[\mathrm{COC}]+18,454[\mathrm{NCOC}]$ and Karickhoff 1981 model being $K_{\mathrm{d}}=14,918$ [OC]

\begin{tabular}{llll}
\hline & Model & $\begin{array}{l}\text { Faardrup } \\
\text { CV (RMSE) }\end{array}$ & $\begin{array}{l}\text { Estrup } \\
\text { CV (RMSE) }\end{array}$ \\
\hline All Samples & Soares et al. model II & 0.08 & 0.37 \\
& Karickhoff 1981 & 0.16 & 0.24 \\
Samples with OC $<0.04 \mathrm{~kg} \mathrm{~kg}^{-1}$ & Soares et al. model II & 0.07 & 0.11 \\
and Dexter $n<10$ & Karickhoff 1981 & 0.12 & 0.11 \\
\hline
\end{tabular}




\section{Faardrup}

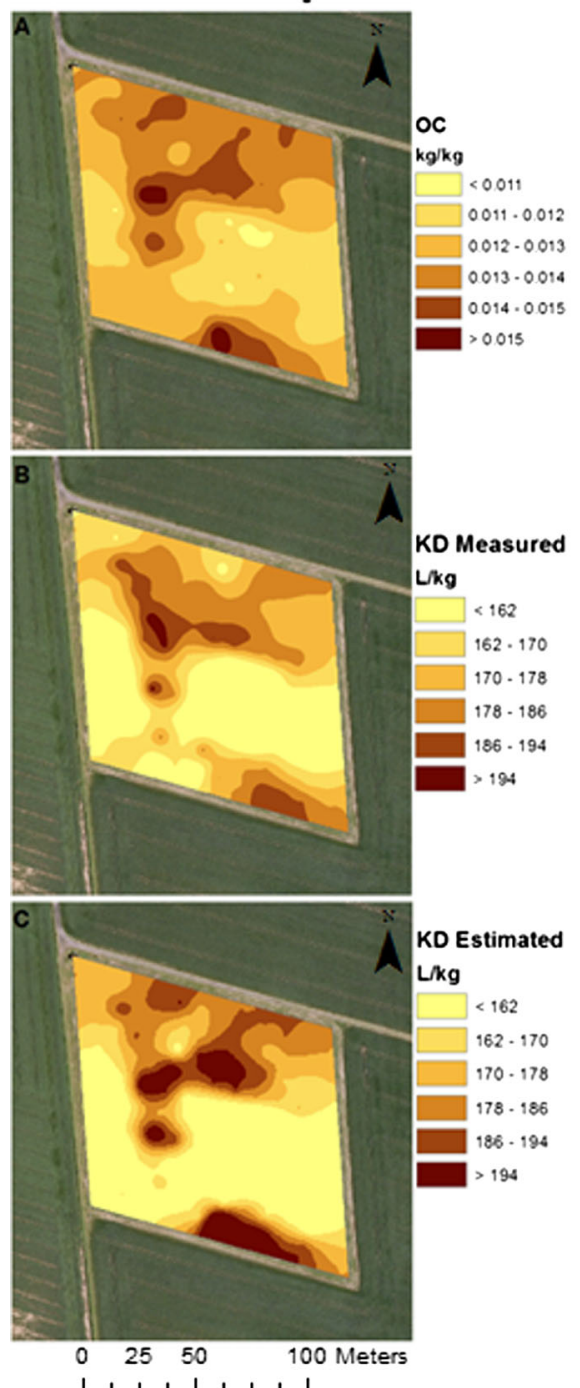

\section{Estrup}

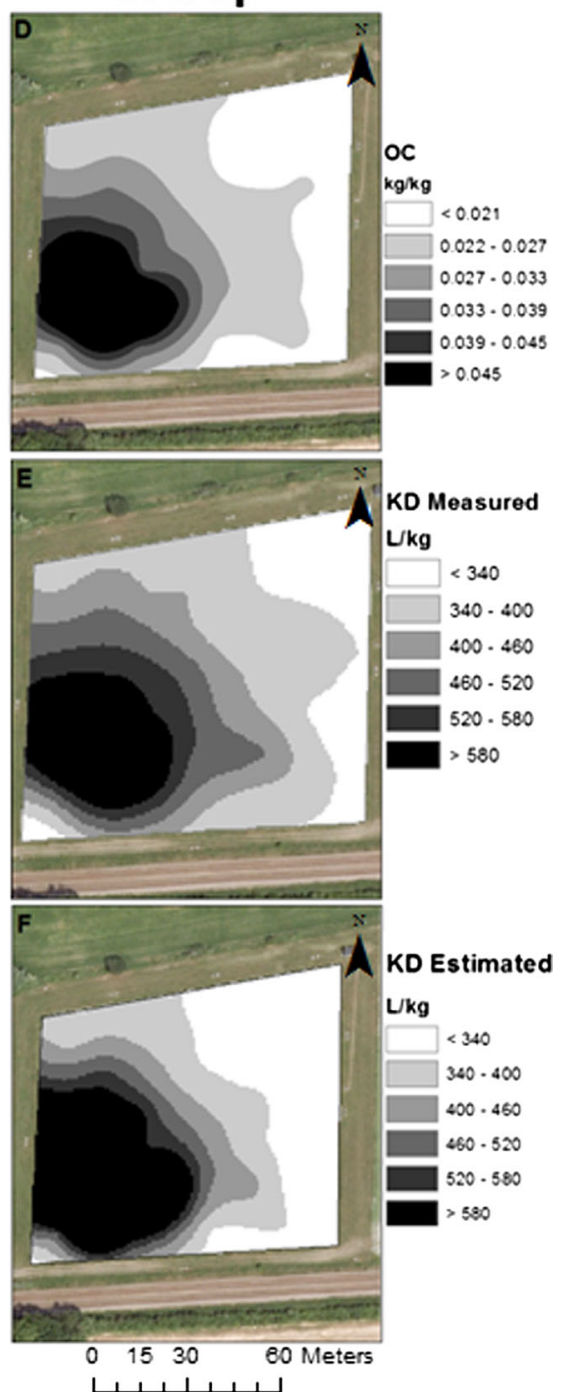

Fig. 4 Contour maps of OC (a, d), $K_{\mathrm{d}}$ measured $(\mathbf{b}, \mathbf{e})$ and $K_{\mathrm{d}}$ estimated from Soares model II at Faardrup (c) and Estrup (f)

these areas is their higher $\mathrm{pH}$ and $\mathrm{OC}$ values. As explained above, phenanthrene sorption in soil is limited by a high pH (Murphy et al. 1990; Laor et al. 1998). In general, at Faardrup (Fig. 5a), the model captured better the sorption variability in areas with lower OC contents $\left(<0.013 \mathrm{~kg} \mathrm{~kg}^{-1}\right.$ ), whereas at Estrup (Fig. 5c) better prediction was achieved in areas with an OC content ranging from 0.027 to $0.039 \mathrm{~kg} \mathrm{~kg}^{-1}$. At Estrup (Fig. 5c, d), the model slightly underestimated $K_{\mathrm{d}}$, for areas with an $\mathrm{OC}$ content lower than $0.04 \mathrm{~kg} \mathrm{~kg}^{-1}$; for higher OC contents, the measured values deviated from the model commensurate with increasing OC content. The model overestimated sorption capacity in the areas where the OC content was high, causing unrealistic predictions of phenantrene-leaching risk. In addition, these areas can be more exposed to facilitated transport of phenanthrene by dissolved organic carbon (Magee et al. 1991).

\subsection{Prediction of Retardation Factor and Environmental Implications}

The type of land use and irrigation rates, along with its source of origin (mainly atmospheric) influences PAH concentrations and its distribution patterns in soil (Wilcke 2000). The soil structure and the available water 

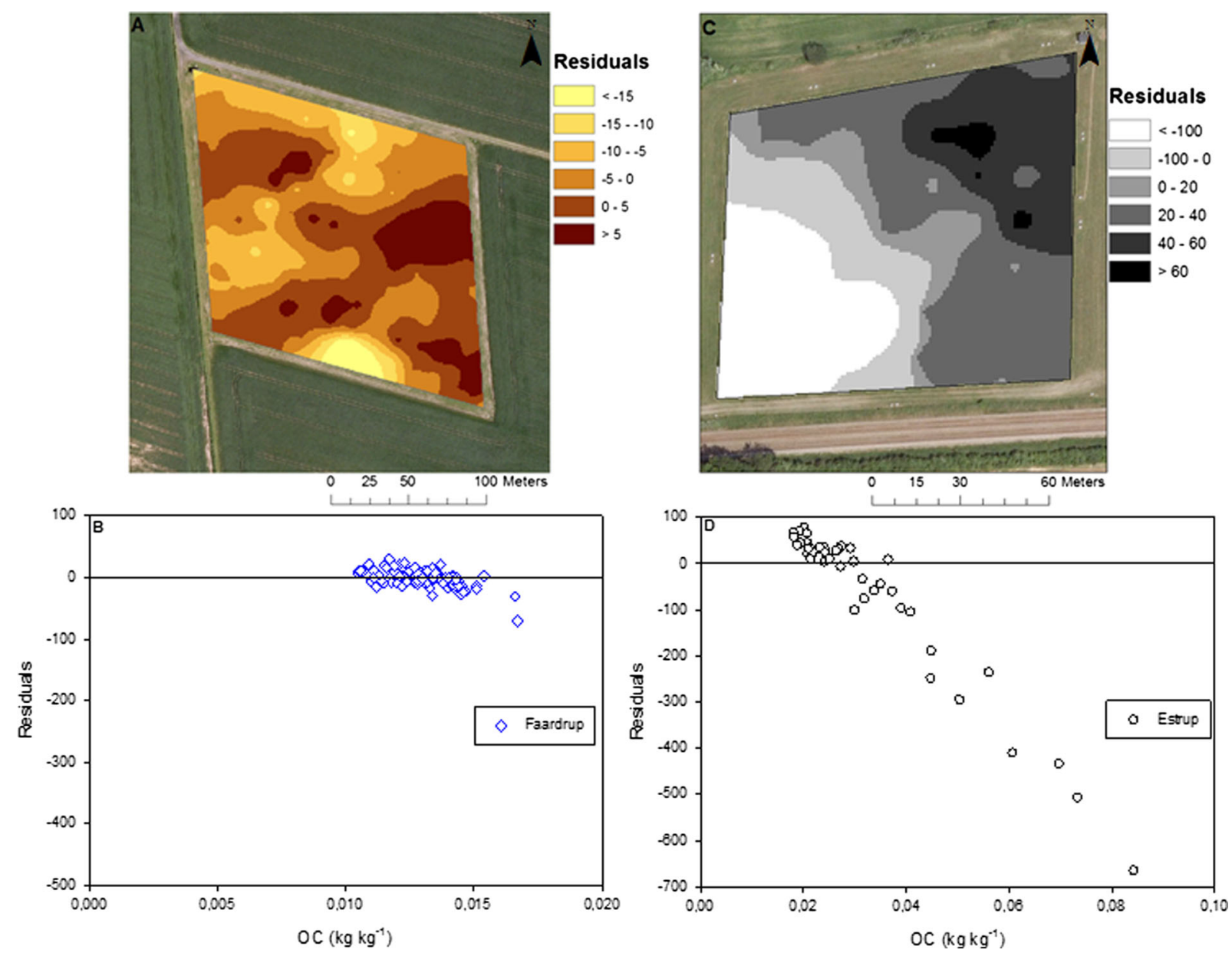

Fig. 5 Contour maps of residuals between $K_{\mathrm{d}}$ measured and $K_{\mathrm{d}}$ estimated for Faardrup (a), and Estrup (c). Residuals as a function of OC for Faardrup (b), and Estrup (d). Soares model II applied

content are the main factors governing the risk of contamination within a soil ecosystem. To get an overview of the leaching risk through the soil profile, the retardation factor $(R)$ is commonly used (e.g. Magee et al. 1991):

$R=1+\left(\frac{\text { Bulk Density }}{\text { Water Content }}\right) \times K_{d(\text { estimated })}$

Values for bulk density and the available water content $\left(\mathrm{cm}^{3} \mathrm{~cm}^{-3}\right)$ were obtained from the $20 \times 20-\mathrm{cm}$ cores (Table 1).

The distribution of the retardation factors at field scale is shown in Fig. 6a, b. A strong correlation was found between $R$ and OC at Estrup (Fig. 6c), where bulk density and water content were found to be controlled by the OC content. There was no effect of OC on these physical properties in Faardrup. According to the high positive correlation between $K_{\mathrm{d}}$ and $R$ for Estrup ( $r=$ $0.90)$, OC largely controlled the retardation of phenanthrene. Additional factors appeared to influence the behaviour at Faardrup. The higher $R$ values $(R>1000)$ in this field were found in the southernmost areas, presumably as a result of a higher sorption level partly because of the high OC contents; the relationship was not straightforward, emphasizing the role of soil structure. At Estrup, the higher $R$ values were more straightforwardly related to the higher OC contents, following the tendency of the previously identified correlation of OC with $K_{\mathrm{d}}$.

Several studies have analysed the influence of various OC fractions on PAH mobilization and retardation. Magee et al. (1991) worked with two soils with different OC contents $\left(0.0011\right.$ and $\left.0.0313 \mathrm{~kg} \mathrm{~kg}^{-1}\right)$. They found 


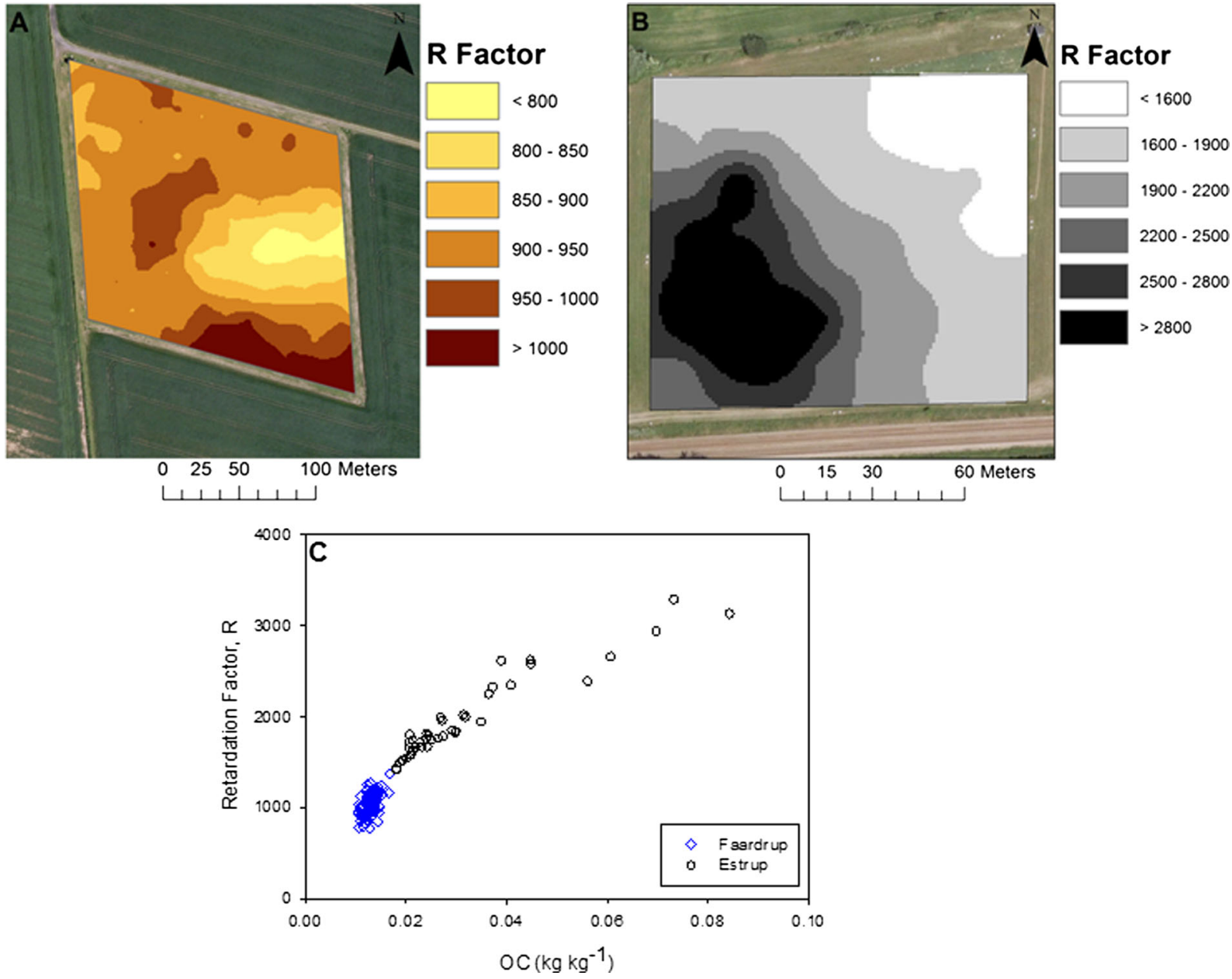

Fig. 6 Contour maps of retardation factor $(R)$ for Faardrup (a) and Estrup (b). $R$ as a function of OC, for both fields (c). Soares model II applied

that carrier-enhanced transport was more significant for the most hydrophobic compounds and at high levels of dissolved OC, although this was counterbalanced by an increase in R. The fractions of OC (e.g. NCOC) should therefore also be considered, on par with the mineral fraction, bulk density and soil water content, as suggested by Luo et al. (2008), among others. Loll and Moldrup (2000) found that, depending on soil type (e.g. sandy loam), other parameters such as saturated hydraulic conductivity could be more important than OC for leaching risk. Any estimation of phenanthrene mobility based on $\mathrm{OC}$ alone could therefore be misleading.

In conclusion, OC largely controlled the sorption of phenanthrene at field scale. However, this study suggests that it is important to take into account the different types of $\mathrm{OC}$ as well as OC interactions with clay, since it seems that for soils with lower OC contents, such as Faardrup, there are probably also other processes governing phenanthrene transport. For such instances, NCOC-based models, such as the Soares et al. model II may be better able to predict sorption.

\section{Conclusions}

In agreement with previous studies, OC was found to be the most important factor for the sorption of phenanthrene, particularly if $\mathrm{OC}$ was above $0.01 \mathrm{~kg} \mathrm{~kg}^{-1}$. For OC levels above $0.04 \mathrm{~kg} \mathrm{~kg}^{-1}$, a decrease was observed in the ability of OC to retain phenanthrene. In general, weaker correlations were found at Faardrup, suggesting 
that there were more drivers at play in this particular field. From our study, the following conclusions can be drawn:

1. The establishment of a subset (samples with Dexter $n<10$ and OC content $<0.04 \mathrm{~kg} \mathrm{~kg}^{-1}$ ) revealed a joint $K_{\mathrm{OC}}$ for both fields of $15,267 \mathrm{~L} \mathrm{~kg}^{-1}$, which is close to the Karickhoff 1981 model value of $14,918 \mathrm{~L} \mathrm{~kg}^{-1}$. Therefore, by selecting this threshold, we suggest that the model can be applied to soils with OC contents of up to $0.04 \mathrm{~kg} \mathrm{~kg}^{-1}$.

2. The NCOC component was found to be determinant, especially for lower OC contents (e.g. Faardrup). Likewise, the complexation of OC by clay was found to reduce the affinity between phenantrene and $\mathrm{OC}$; therefore, $\mathrm{COC}$ should not be omitted in order to improve $K_{\mathrm{d}}$ predictions.

3. Despite a good correlation between $\mathrm{OC}, K_{\mathrm{d}}$ and R at Estrup, this was not the case for Faardrup, where possibly more players influenced the process of leaching and sorption. Therefore, for a better understanding of the environmental repercussions of phenanthrene mobility, not only should the different fractions of $\mathrm{OC}$ be considered but also soil structural parameters.

\begin{abstract}
Acknowledgments This research was funded as part of the large framework project Soil Infrastructure, Interfaces and Translocation Processes in Inner Space ("Soil-it-is") by the Danish Research Council for Technology and Production Sciences, by the Danish Pesticide Leaching Assessment Programme (www. pesticidvarsling.dk), by the European Union (FEDER funds through COMPETE) and by Fundação para a Ciência e Tecnologia (FCT) through the project Pest-C/EQB/LA0006/ 2013. António Soares is grateful to FCT for his doctoral research grant (SFRH/BD/69565/2010) financed through POPH-QREN, Tipologia 4.1 e Formação Avançada, and subsidized by Fundo Social Europeu and Ministério da Ciência, Tecnologia e Ensino Superior. M. Paradelo is financially supported by a postdoctoral contract from the Plan I2C, Xunta de Galicia. To all financing sources, the authors are greatly indebted.
\end{abstract}

\section{References}

Abdul, A. S., Gibson, T. L., \& Rai, D. N. (1987). Statistical correlations for predicting the partition-coefficient for nonpolar organic contaminants between aquifer organic-carbon and water. Hazardous Waste \& Hazardous Materials, 4, $211-$ 222.
Amellal, S., Boivin, A., Ganier, C. P., \& Schiavon, M. (2006). High sorption of phenanthrene in agricultural soils. Agronomy for Sustainable Development, 26, 99-106.

Cachada, A., Pereira, M. E., da Silva, E. F., \& Duarte, A. C. (2012). Sources of potentially toxic elements and organic pollutants in an urban area subjected to an industrial impact. Environmental Monitoring and Assessment, 184, 15-32.

Celis, R., de Jonge, H., de Jonge, L. W., Real, M., Hermosin, M. C., \& Cornejo, J. (2006). The role of mineral and organic components in phenanthrene and dibenzofuran sorption by soil. European Journal of Soil Science, 57, 308-319.

Charnay, M., Tuis, S., Coquet, Y., \& Barriuso, E. (2005). Spatial variability in 14C-herbicide degradation in surface and subsurface soils. Pest Management Science, 61, 845-855.

Chung, N., \& Alexander, M. (2002). Effect of soil properties on bioavailability and extractability of phenanthrene and atrazine sequestered in soil. Chemosphere, 48, 109-115.

Cousin, I. T., Beck, K., \& Jones, K. J. (1999). A review of the processes involved in the exchange of semi-volatile organic compounds (SVOC) across the air-soil interface. Science of Total Environment, 228, 5-24.

de Jonge, L. W., de Jonge, H., Moldrup, P., Jacobsen, O. H., \& Christensen, B. T. (2000). Sorption of prochloraz on primary soil organomineral size separates. Journal of Environmental Quality, 29, 206-213.

de Jonge, L. W., Moldrup, P., de Jonge, H., \& Celis, R. (2008). Sorption and leaching of short-term-aged PAHs in eight European soils: link to physicochemical properties and leaching of dissolved organic carbon. Soil Science, 173, 13-24.

DeLapp, R. C., \& LeBoeuf, E. J. (2004). Thermal analysis of whole soils and sediment. Journal of Environmental Quality, 33, 330-337.

Dexter, A. R., Richard, G., Arrouay, D., Czyz, E. A., Jolivet, C., \& Duval, O. (2008). Complexed organic matter controls soil physical properties. Geoderma, 144, 620-627.

Gaultier, J., Farenhorst, A., \& Crow, G. (2006). Spatial variability of soil properties and 2,4-D sorption in a hummocky field as affected by landscape position and soil depth. Canadian Journal of Soil Science, 86, 89-95.

Gee, G. W., \& Or, D. (2002). Methods of soil analysis, part 4physical methods (5th ed.). Madison: Soil Science Society of America.

Goderya, F. S. (1998). Field scale variations in soil properties for spatially variable control: a review. Journal of Soil Contamination, 7, 243-264.

Gregorich, E., \& Anderson, D. (1985). Effects of cultivation and erosion on soils of four toposequences in the Canadian prairies. Geoderma, 36, 343-354.

Hassett, J. J., \& Banwart, W. L. (1989). The sorption of nonpolar organics by soils and sediments. In B. L. Sawhney \& K. Brown (Eds.), Reactions and movement of organic chemicals in soils. Madison: SSSA Spec. Publ. 22, Soil Science Society of America Inc.

Huang, W., Peng, P., Yu, Z., \& Fu, J. (2003). Effects of organic matter heterogeneity on sorption and desorption of organic contaminants by soils and sediments. Applied Geochemistry, 18, 955-972.

Jones, K. D., \& Tiller, C. L. (1999). Effect of solution chemistry on the extent of binding of phenanthrene by a soil humic acid: a 
comparison of dissolved and clay bound humic. Environmental Science \& Technology, 33, 580-587.

Karickhoff, S. W. (1981). Semi-empirical estimation of sorption of hydrophobic pollutants on natural sediments and soils. Chemosphere, 10, 833-846.

Karickhoff, S. W., Brown, D. S., \& Scott, T. A. (1979). Sorption of hydrophobic pollutants on natural sediments. Water Research, 13, 241-248.

Kiersch, K., Jandl, G., Meissner, R., \& Leinweber, P. (2010). Small scale variability of chlorinated POPs in the river Elbe floodplain soils (Germany). Chemosphere, 79, 745-753.

Kjaer, J., Olsen, P., Bach, K., Barlebo, H. C., Ingerslev, F., Hansen, M., \& Sorensen, B. H. (2007). Leaching of estrogenic hormones from manure-treated structured soils. Environmental Science \& Technology, 41, 3911-3917.

Kjaer, J., Rosenbom, A. E., Brusch, W., Juhler, R. K., Gudmundsson, L., Plauborg, F., Grant, R., \& Olsen, P. (2011). The Danish pesticide leaching assessment programme: monitoring results May 1999-June 2010. Copenhagen: Geological Survey of Denmark and Greenland.

Kumari, K. G. I. D., Moldrup, P., Paradelo, M., \& de Jonge, L. W. (2014). Phenanthrene sorption on bio-char amended soils: application rate, aging, and physicochemical properties of soil. Water, Air, and Soil Pollution, 225, 2105.

Laor, Y., Farmer, W. J., Aochi, Y., \& Strom, P. (1998). Phenanthrene binding and sorption to dissolved and to mineral-associated humic acid. Water Research, 32, 19231931.

Liang, Y., Zhang, X., Wang, J., \& Li, G. (2012). Spatial variations of hydrocarbon contamination and soil properties in oil exploring fields across China. Journal of Hazardous Materials, 241-242, 371-378.

Lindhardt, B., Abildrup, C., Vosgerau, H., Olsen, P., Torp, S., Iversen, B. V., Jorgensen, J. O., Plauborg, F., Rasmussen, P., \& Gravesen, P. (2001). The Danish Pesticide Leaching Assessment Programme: Site characterization and monitoring design. (ISBN 87-7871-094-4). Available from Geological Survey of Denmark and Greenland.

Loll, P., \& Moldrup, P. (2000). Stochastic analyses of field-scale pesticide leaching risk as influenced by spatial variability in physical and biochemical parameters. Water Resources Research, 36, 959-970.

Luo, L., Zhang, S., \& Ma, Y. (2008). Evaluation of impacts of soil fractions on phenanthrene sorption. Chemosphere, 72, 891896.

Magee, B. R., Lion, L. W., \& Lemley, A. T. (1991). Transport of dissolved organic macromolecules and their effect on the transport of phenanthrene in porous media. Environmental Science \& Technology, 25, 323-331.

Muller, K., Smith, R. E., James, T. K., Holland, P. T., \& Rahman, A. (2003). Spatial variability of atrazine dissipation in an allophanic soil. Pest Management Science, 59, 893-903.

Murphy, E. M., Zachara, J. M., \& Smith, S. C. (1990). Influence of mineral-bound humic substances on the sorption of hydrophobic organic compounds. Environmental Science \& Technology, 24, 1507-1516.

Nielsen, D. R., Biggar, J. W., \& Erh, K. T. (1973). Spatial variability of field-measured soil-water properties. Hilgardia, 42, 215-259.
Njoroge, B. N. K., Ball, W. P., \& Cherry, R. S. (1998). Sorption of 1,2,4-trichlorobenzene and tetrachloroethene within an authigenic soil profile: changes in KOC with soil depth. Journal of Contaminant Hydrology, 29, 347-377.

Ping, L., Lou, Y., Wu, L., Qian, W., Song, J., \& Christie, P. (2006). Phenanthrene adsorption by soils treated with humic substances under different $\mathrm{pH}$ and temperature conditions. Environmental Geochemistry and Health, 28, 189-195.

Ran, Y., Huang, W., Rao, P. S. C., Liu, D., Sheng, G., \& Fu, J. (2002). The role of condensed organic matter in the nonlinear sorption of hydrophobic organic contaminants by a peat and sediments. Journal of Environmental Quality, 31, 19531962.

Reeves, W. R., McDonald, T. J., Cizmas, L., \& Donnely, K. C. (2004). Partitioning and desorption behavior of polycyclic aromatic hydrocarbons from disparate sources. Science of Total Environment, 332, 183-192.

Schlautman, M. A., \& Morgan, J. (1993). Effects of aqueous chemistry on the binding of polycyclic aromatic hydrocarbons by dissolved humic materials. Environmental Science \& Technology, 27, 961-969.

Schwarzenbach, R. P., \& Westall, P. (1981). Transport of nonpolar organic compounds from surface water to groundwater. Laboratory sorption studies. Environmental Science \& Technology, 15, 1360-1367.

Site, D. (2000). Factors affecting sorption of organic compounds in natural sorbent/water systems and sorption coefficients for selected pollutants. A review. Journal of Physical and Chemical Reference Data, 30, 187-439.

Soares, A. A., Minh, L. N., Vendelboe, A. L., Schjonning, P., \& de Jonge, L. W. (2013). Sorption of phenanthrene on agricultural soils. Water, Air, and Soil Pollution, 224, 1519-1530.

Styrishave, B., Bjorklund, E., Johnsen, A., \& Halling-Sorensen, B. (2012). The spatial heterogeneity of polycyclic aromatic hydrocarbons in soil depends on their physico-chemical properties. Water, Air, and Soil Pollution, 223, 969-977.

Umali, B. P., Oliver, D. P., Ostendorf, B., Forrester, S., Chittleborough, D. J., Hutson, J. L., \& Kookana, R. S. (2012). Spatial distribution of diuron sorption affinity as affected by soil, terrain and management practices in an intensively managed apple orchard. Journal of Hazardous Materials, 217-218, 398-405.

Vinther, F. P., Brinch, U. C., Elsgaard, I., Fredslund, L., Iversen, B. V., Torp, S., \& Jacobsen, C. S. (2008). Field-scale variation in microbial activity and soil properties in relation to mineralization and sorption of pesticides in a sandy soil. Journal of Environmental Quality, 37, 1710-1718.

Wauchope, R. D., Yeh, S., Linders, J. B. H. J., Kloskowski, R., Tanaka, K., Rubin, B., Katayama, A., Kördel, W., Gerstl, Z., Lane, M., \& Unsworth, J. B. (2002). Pesticide soil sorption parameters: theory, measurement, uses, limitations and reliability. Pest Management Science, 58, 419-445.

Wilcke, W. (2000). Polycyclic aromatic hydrocarbons (PAHs) in soil-a review. Journal of Plant Nutrition and Soil Science, 163, 229-248.

Yang, L., Jin, M., Tong, C., \& Xie, S. (2013). Study of dynamic sorption and desorption of polycyclic aromatic hydrocarbons in silty-clay soil. Journal of Hazardous Materials, 244-245, 77-85. 